\title{
THREE CASE STUDIES IN CURRENT LEIBNIZ SCHOLARSHIP
}

\author{
MIKHAIL G. KATZ, KARL KUHLEMANN, DAVID SHERRY, \\ AND MONICA UGAGLIA
}

\begin{abstract}
We examine some recent scholarship on Leibniz's philosophy of the infinitesimal calculus. We indicate difficulties that arise in articles by Bassler, Knobloch, and Arthur, due to a denial to Leibniz's infinitesimals of the status of mathematical entities violating Euclid V Definition 4.
\end{abstract}

January 7, 2022

\section{Contents}

1. Three case studies

2. Creatures and infinitesimals

2.1. Syncategorematic infinitesimals?

2.2. Infinitely small things

2.3. Bassler vs Jesseph

2.4. Where do infinitesimals fit in?

2.5. Relatively more freestanding symbols

3. Knobloch's evolution on infinitesimals, bounded infinity 6

3.1. Early writings 6

3.2. Knobloch vs Breger 7

3.3. Quantifiers, Weierstrass, and the Epsilontik 9

4. An Arthurian Cantor-Leibniz séance 11

4.1. Evolution of Arthur's views

4.2. 'Testament to the necessity of infinite number' 13

5. Conclusion 15

Acknowledgment 15

2020 Mathematics Subject Classification. Primary 01A45, Secondary 01A85, 01A90, 26E35.

Key words and phrases. infinitesimals; infinity; syncategorematic; Leibniz; Cantor. 
Infinitesimal calculus is as much, or as little, about infinitesimals as the business of a variety shop is to sell varieties. - Bassler

\section{Three CASE STUdies}

Leibniz's references to infinity and infinitesimals have been a source of continued debate in current Leibniz scholarship; see e.g., 31 for a comparison of rival viewpoints. Ishiguro developed a so-called syncategorematic interpretation of Leibnizian infinities and infinitesimals in her [28, Chapter 5]. A rival interpretation was developed by Esquisabel and Raffo Quintana in [23, pp. 620, 641].

The bone of contention is the status of Leibnizian infinitesimals: are they mathematical entities? Ishiguro denies this, and seeks to interpret each occurrence of the term infinitesimal in Leibniz as merely shorthand for more long-winded exhaustion-style arguments exploiting only "ordinary" numbers. Such a state of affairs is sometimes referred to as syncategorematicity. As in Mediaeval logic syncategoremata were the parts of speech lacking a definite reference of their own and depending instead on other parts (categoremata) in order to acquire a definite reference, syncategorematic infinitesimals depend on other mathematical entities, namely the ones involved in the method of exhaustion. See also [30, Section 3].

Esquisabel and Raffo Quintana, while acknowledging the fictional nature of Leibnizian infinitesimals, nonetheless accord to them the status of mathematical entities. Bascelli et al. [13], Błaszczyk et al. [17, and Katz et al. [30] similarly accord to Leibniz's fictional infinitesimals the status of mathematical entities that do not idealize anything in nature. Blåsjö's approach in [15] is largely compatible with such a reading.

By contrast, the proponents of Ishiguroan interpretations deny the Leibnizian infinitesimals the status of mathematical entities violating Euclid V, Definition 4 (closely related to the so-called Archimedean axiom). Focusing on three examples, taken from the work of Bassler (Section 2), Knobloch (Section 3) and Arthur (Section 4), we signal some difficulties such approaches encounter in interpreting Leibniz. 
In Section 2 we present the kind of problems which result from conflating concepts related to the mathematical and the physical realm. In Section 3 we outline the difficulty which arises from conflating, in mathematics, the Leibnizian notions of bounded and unbounded infinite. Finally, a situation where both kinds of conflation are present is analyzed in Section 4.

\section{Creatures AND infinitesimals}

The locution syncategorematic infinitesimal occurs nowhere in Leibniz's known work. It is coined on the model of the expression syncategorematic infinite, a crucial concept in Leibniz's thought.

2.1. Syncategorematic infinitesimals? Applying to the infinite the Mediaeval distinction between categorematic and syncategorematic use of a term (see Section 11), one can say that Leibniz's indefinite i.e., unbounded infinite (see [30, Section 4.3]) is syncategorematic, because it does not refer to any properly infinite entity. Rather, it means that given a finite entity, such as a number or a segment, one can always take a bigger finite one, and so on, indefinitely. In other words, the quantitative infinite must be intended always in a distributive way, so that for Leibniz there is no collective quantitative infinite. On this definition see for instance Bassler's [14, p. 855, note 15], singled out by Richard Arthur for special praise:

"Bassler's erudite footnote on the syncategorematic and categorematic in his 1998, 855, n. 15." (Arthur [5], 2015, p.145, note 15$)$

On the relation between Leibniz's syncategorematic infinite and Aristotle's potential infinite see [56].

A similar notion of syncategorematicity is applied by Arthur, Bassler, and others to infinitesimals. Just as a syncategorematic infinite refers to the procedure of indefinitely increasing a finite quantity, which remains at all times finite, so also syncategorematic infinitesimals refer to the procedure of indefinitely decreasing a finite (more precisely, assignable) quantity, which remains at all times finite. On this reading, infinitesimals are a shorthand for Archimedean exhaustion-style procedures.

The thesis attributing such syncategorematic infinitesimals to Leibniz depends on two main assumptions: Leibniz' alleged claims of the non-existence of infinitesimals, and the identification of unbounded infinities (infinita interminata) as reciprocal of infinitesimals. In this section we discuss Bassler's version of the first assumption, starting 
with a key passage from a 20 june 1702 letter to Varignon, where Leibniz made the following intriguing comment:

Je croy qu'il n'y a point de creature au dessous de la quelle il n'y ait une infinité de creatures, cependant je ne crois point qu'il y en ait, ny même qu'il y en puisse avoir d'infiniment petites et c'est ce que je crois pouvoir demonstrer. [44, p. 110]

The French noun créature (spelled creature by Leibniz) is feminine. The qualifier infiniment petites accords with creatures and is therefore also feminine. Thus, Leibniz is asserting that there could not be infinitesimal (material) creatures. A fragment of Leibniz's sentence is quoted by Bassler in translation. We note the following four points.

2.2. Infinitely small things. Bassler suppresses the beginning of the sentence and reproduces only its conclusion as follows:

[Leibniz] believes he can prove 'that there are not, nor could there be, any infinitely small things'. [14, p. 873]

The sentence fragment quoted (in translation) by Bassler, taken out of context, may suggest that Leibniz asserts the impossibility of infinitesimals. Read in context, it is clear that the sentence merely asserts the impossibility of material infinitesimals.

Bassler is not alone in seeking to exploit this letter to Varignon in support of a thesis denying the status of mathematical entities to infinitely small quantities. A similar truncation maneuver occurs in Schubring, who purports to quote Leibniz as follows:

I do not believe that there are or even that there could be infinitely small quantities, and that is what I believe to be able to prove. It is that simple substances (that is, those that are not aggregated objects) are truly indivisible, but they are not material and are but principles of action. (Leibniz as rendered by Schubring in [55], 2005, p. 173, lines -12 through -9; emphasis added)

Notice that Schubring has Leibniz speak of "infinitely small quantities" in this passage, whereas Leibniz himself only mentioned "creatures infiniment petites." The modification is convenient for scoring an anti-infinitesimal point, but distorts Leibniz's intention. Additional instances of truncation of Leibnizian passages resulting in distorting their meaning are presented in [13].

2.3. Bassler vs Jesseph. Bassler criticizes Jesseph ([29], 1989) in the following terms: 
[Jesseph's] suggestion that we can use Leibniz's attitude concerning the segregation of metaphysical from mathematical problems as a resolution of the 'ambiguity' in Leibniz's use of infinitesimals ... seems to me hand-waving at best and circular at worst. [14, p. 868, continuation of note 57]

According to Bassler, "The problem, of course, is that such a "radical thesis' itself requires a metaphysical justification" (ibid.; emphasis in the original). Bassler provides no further details concerning 'the problem', or why a 'segregation of metaphysical from mathematical' would be so problematic in his opinion.

In mature Leibniz, one finds three distinct realms: (1) the real metaphysical realm of substances or monads, (2) the phenomenal physical realm; (3) the ideal mathematical realm. The desegregation, or more precisely conflation, of these realms is what led Bassler to misrepresent the Leibnizian position, as noted in Section 2.2 .

2.4. Where do infinitesimals fit in? Bassler lodges the following claim against infinitesimals:

[E]xisting infinitesimals, whether ideal or real, fit nowhere. This is the ultimate consequence of Leibniz's understanding that in the realm of quantity there are no infinite or infinitesimal wholes: the quantitative infinite is identified with the indefinite or unlimited. ([14], p. 872; emphasis on 'wholes' added)

The claim suffers from a conflation of quantity and multitude 11 Leibniz held that infinite multitude taken as a whole (i.e., infinita interminata) contradicts the part-whole principle (see [30, Section 4.1]). However, Bassler provides no evidence that Leibniz viewed infinitesimals and infinite quantities (infinita terminata) as contradictory.

2.5. Relatively more freestanding symbols. Bassler proposes a syncategorematic reading of infinitesimals similar to Ishiguro's:

Leibniz's recourse to these incomparable quantities is exclusively symbolic: they are mathematical symbols whose true interpretation can only be given in terms of their replacement, in any given context, by other, relatively more freestanding symbols. ... Consequently Leibniz will later declare that infinitesimals and infinitely large magnitudes are "convenient fictions." 62 [14, p. 869]

Here Bassler seeks to interpret fictionality in terms of syncategorematicity. Bassler's footnote 62 attached to this passage is significant

\footnotetext{
${ }^{1} \mathrm{~A}$ similar conflation in Rabouin and Arthur [51] is analyzed in [30, Section 4.2].
} 
for our purposes. The footnote contains the following passage from Leibniz's letter to Masson:

The infinitesimal calculus is useful with respect to the application of mathematics to physics; however, that is not how I claim to account for the nature of things [la nature des choses]. For I consider infinitesimal quantities to be useful fictions. (Leibniz [45] as translated by Ariew in [46], p. 230)

However, Bassler's interpretation of the letter to Masson involves a conflation of mathematics and nature. A similar conflation occurs in the work of Rabouin and Arthur [51]; for details see [30, Section 2.2] as well as Section 4.2 below.

\section{Knobloch's Evolution on infinitesimals, BOUNDED INFINITY}

The definition of syncategorematic infinitesimals is grounded in the assumption that for Leibniz the counterparts of infinitesimals are unbounded infinities. However, much evidence to the contrary exists in Leibniz's oeuvre. He specifies repeatedly that the counterparts of infinitesimals are bounded infinities (infinita terminata), rather than unbounded infinities (infinita interminata).

In this section we trace Knobloch's analysis of the bounded infinite in Leibniz, and his evolving views concerning the Leibnizian infinitesimal geometry and calculus.

3.1. Early writings. In Knobloch's early writings on Leibniz, infinitesimals were less than any assignable quantity, Breger was criticized for claiming that bounded infinities were not important later on, and there was no talk of variables (and certainly not of Weierstrass and the Epsilontik).

1989. Thus, in 1989, Knobloch stresses the importance of the distinction between bounded and unbounded infinite in the following terms:

Leibniz discute un problème mathématique qui est en même temps un problème philosophique: l'infini dans les mathématiques, en particulier la différence entre l'infini et l'interminé ... Cette différence est extrêmement importante. L'infini est une quantité qui est plus grande qu'une quantité quelconque assignable ou qu'une quantité qu'on peut désigner par des nombres. [34, p. 166] 
Here l'infini is the infinitum terminatum, defined as being greater than any assignable quantity 2 Meanwhile, l'interminé is the unbounded infinity (see [8, Section 2.2]). Significantly, there is no mention of variables in the 1989 text.

1990. Knobloch analyzes Leibniz's manuscript De Quadratura Arithmetica (1676) in a 1990 text, and writes:

(1) L'action de l'esprit par laquelle nous mesurons les espaces infinis s'appuie sur une fiction, sur une ligne, qui est terminée selon la présupposition, mais infinie. [35, p. 39] (emphasis added)

(2) Si l'abscisse $\mu(\mu)$ est infiniment petite, l'ordonnée $(\mu) \lambda$ est infiniment longue, c'est-à-dire plus grande qu'une droite quelconque désignable, le rectangle effectué par la droite infinie et la droite infiniment petite est égal à un carré fini constant selon la nature de l'hyperbole. [35, p. 41]

(3) [Leibniz] dit dans une note marginale d'un écrit de Schuller: J'ai fait toujours une différence entre immense et interminé, entre celui auquel on ne peut ajouter rien et celui qui est plus grand qu'un nombre assignable. ([35, p. 42]; emphasis added)

(4) L'infiniment petit est défini par 'plus petit qu'une grandeur assignable' (minus quavis assignabili quantitate) 3 [35, p. 49]

Here the immense, referring to infinita terminata, is again contrasted with unbounded infinity. Knobloch's 1990 article similarly contains no description of infinitesimals either as variables or as logical fictions concealing alternating quantifiers.

3.2. Knobloch vs Breger. The issue of the bounded infinite was debated by Breger and Knobloch in the 1990s.

1994. In 1994, Knobloch takes issue with Breger in defense of the bounded infinite:

All the more surprising is the fact that a contrary remark is found in the secondary literature which appeared very recently (Breger 1990, 65): 'Leibniz seems to have called in question the utility of the bounded infinite already during his stay in Paris. Later on he seems to have abandoned the bounded infinite in mathematics.' The contrary is correct. [36, p. 268]

\footnotetext{
${ }^{2}$ Here Knobloch offers no reservations concerning such a Leibnizian definition of infinitum terminatum in terms of assignable quantities; cf. note 3.

${ }^{3}$ This definition of infinitesimal as smaller than every assignable quantity is, appropriately, not accompanied by any vanishing claims, unlike its later occurrences in Knobloch's writing; see main text at note 9.
} 
The reference is to Breger's article $([18,1990)$. Knobloch then goes on to provide evidence refuting Breger's claims. Knobloch writes further:

[Leibniz] accepts different orders of infinite lines and different infinitely small lines. If we choose an arbitrary finite line $\ell_{f}$, we find an infinitely small line $\ell_{i s}$ and an infinite line $\ell_{i}$, so that we obtain the equation $\ldots \ell_{f}^{2}=\ell_{i} \cdot \ell_{i s}$ [36, p. 268]

The passage appears to distinguish between three orders of magnitude among Leibnizian lines (i.e., segments) - infinitesimal, finite, and infinite - typical of non-Archimedean systems. The 1994 article similarly contains no description of infinitesimals as variables.

1999. Knobloch has been writing about Leibnizian infinitesimal geometry and analysis at least since ([33], 1978). Over two decades later in 1999, one finds Knobloch for the first time describing infinitesimals as variable quantities:

Leibniz defined 'lines', that is linear indivisibles as infinitely small rectangles, that is as variable quantities 4 His starting point was a quantification of the notion of indivisibles. [37, p. 95]

Yet in the same paper one still finds the reading of "not appearing in nature" type:

The demonstrations of the forty-five theorems that follow [in DQA] are based on this concept of infinitely small and infinite quantities, that is, quantities which are, according to his definition, positive, but smaller than any given quantity or larger than any given quantity. The decisive aspect is that they are quantities, fictive ones certainly, because they were introduced by a fiction, but quantities nevertheless. It does not matter whether they appear in nature or not, because they allow abbreviations for speaking, for thinking, for discovering, and for proving. (ibid.; emphasis added)

Knobloch's 1999 interpretation of fictionality in terms of not necessarily "appearing in nature" is consonant with the reading developed in [32], [8], and 30].

2002. In 2002, Knobloch still quotes the Leibnizian

'law of continuity': The rules of the finite remain valid in the domain of the infinite. [38, p. 67]

\footnotetext{
${ }^{4}$ Similar claims concerning variable quantities appear in a 2018 article by Knobloch; see Section 3.3 .
} 
To escape vacuity, such a law would apparently need to refer to a notion of an infinite beyond merely a variable finite - for why wouldn't the rules of the finite naturally remain valid in the domain of the variable finite, even without invoking any special laws or "metaphysical principles of continuity" (De Risi [21], 2019, p. 124)?

3.3. Quantifiers, Weierstrass, and the Epsilontik. In Knobloch's later writings, one detects a change of attitude toward Leibnizian infinitesimals.

2008. Thus, by 2008, alternating quantifiers make their appearance, as Knobloch compares Leibniz and Euler:

We might sum up the crucial difference between Euler's and Leibniz's definitions of infinitely small quantities in the following way: Let $i$ be an infinitely small quantity, $g q$ a given quantity, $a q$ an assignable quantity.

Leibniz: For all $g q>0$ there is an $i(g q)>0$ so that $i(g q)<g q$ $\Rightarrow i(g q)$ is a variable quantity.

Euler: For all $i$ and for all $a q>0: \quad i<a q$ $\Rightarrow i=0$.

(Knobloch [39], 2008, p. 180)

Knobloch's analysis of Leibnizian infinitesimals in terms of the quantifier phrase "For all $g q>0$ there is an $i(g q)>0$ so that $i(g q)<g q$ " echoes Ishiguro's syncategorematic alternating quantifier reading; see Section 1. Knobloch's claim of such a dramatic discontinuity in attitude toward infinitesimals between Leibniz and Euler is dubious 5 case in favor of Leibniz-Euler continuity is argued in Bair et al. ([7], 2017).

2012. In later Knobloch, both Weierstrass and the Epsilontik make their appearance, accompanied by (1) a denial of inassignables, and (2) insertion of alternating quantifiers. Thus, in 2012 we learn that

From 1673 he tried different possibilities like smallest, unassignable magnitude, smaller than any assignable quantity. He rightly rejected all of them because there are no smallest quantities and because a quantity that is smaller than any assignable quantity is equal to zero or nothing 6 ... Now [Leibniz] had to answer

\footnotetext{
${ }^{5}$ Cauchy has been similarly the subject of dubious interpretations aimed at denying that he worked with bona fide infinitesimals; for details see [10], [9], [1].

${ }^{6}$ A quantity $Q$ smaller than any assignable quantity is of course necessarily zero provided $Q$ itself is assignable. Such an observation is the last step of a typical argument by exhaustion. However, Knobloch's conclusion does not follow if $Q$
} 
the question: What does it mean to be infinitely small? Still in 1673 he gave an excellent answer: infinitely small means smaller than any given quantity. (Knobloch [40, 2012, pp. 20-21)

Knobloch elaborates:

He again used the mode of possibility and introduced a consistent notion. Its if-then structure - if somebody proposes a quantity, then there will be a smaller quantity - rightly reminds the modern reader of Weierstraßs's $\epsilon$ - $\delta$-language. Leibniz's language can be translated into Weierstraßs's language. (Knobloch [40], 2012, p. 21; emphasis added)

The postulation of such an "if-then structure" is akin to Ishiguro's interpretation. Knobloch's attribution of such a reading to Leibniz as early as 1673 clashes with Arthur's claim that the switch to syncategorematics occurred between february and april of 1676.7 For additional details see [30, Section 3.1].

2018. In 2018, Knobloch writes: "Such a difference or such a quantity [i.e., an infinitesimal] necessarily is a variable quantity" [41, p. 12]. In the same text Knobloch notes that

"the error is smaller than any assignable error and therefore zero ... Such an error necessarily is equal to zero as Leibniz rightly states. For if we assume that such an error is unequal to zero it would have a certain value. But this implies a contradiction against the postulate that the error has to be smaller than any assignable quantity, that is, also smaller than this certain value. Yet, Leibniz explicitly calls such errors infinitely small: We should not try to make things seem better" (ibid.; emphasis added).

The italicized comment appears to imply that something could be better about the Leibnizian remarks on infinitesimals. Actually things seem rather good to the present authors. What Knobloch is bothered by is an apparent tension between the fact that the error is supposed to turn out to be zero rather than merely infinitely small. But the desired

is not assumed to be assignable. This enables inassignable infinitesimals to be both smaller than every assignable quantity and nonzero. See [30, Section 4.5] for a geometric illustration in terms of hornangles. For an analysis of a related misconception in Rabouin [50] see [30, Section 3.2].

${ }^{7}$ Thus, Arthur writes: "For some time, Leibniz appears to have hesitated over this interpretation, and as late as February 1676 he was still deliberating about whether the success of the hypothesis of infinities and the infinitely small in geometry spoke to their existence in physical reality too. But by April [1676], the syncategorematic interpretation is firmly in place" [3, p. 559]. 
conclusion will be correct if the quantity being estimated is assumed to be assignable 8

Also in 2018, we learn that

[Leibniz] himself noticed that the definition "smaller than any assignable" is useless because such a quantity must be necessarily equal to zero. 9 [42, p. 54]

But did Leibniz ever notice such a thing? The impossibility of a nonzero infinitesimal would apparently imply also the impossibility of its reciprocal, the infinita terminata. Yet infinita terminata was staunchly defended by early Knobloch in 1994 against Breger (see Section 3.2).

2022. Most recently (2022?), we learn that

An infinitely small quantity is a variable quantity and can be described in terms of the Weierstrassian epsilon-delta language. 43.

It emerges that according to later Knobloch, the Leibnizian infinite is not so immense after all. We see that the task of declaring Leibniz a Weierstrassian and practitioner of the Epsilontik took Knobloch several decades of work. However, his early writings sampled in Sections 3.1 and 3.2 arguably reflect a more accurate picture of the Leibnizian infinitesimal geometry and calculus.

\section{An Arthurian Cantor-Leibniz séance}

In a 2019 medium, Richard Arthur conjures up a 33-page CantorLeibniz dialogue. Here Arthur endeavors

[to] use this dialogue to argue that the Leibnizian actual infinite constitutes a perfectly clear and consistent third alternative in the foundations of mathematics to the usual dichotomy between the potential infinite (Aristotelianism, intuitionism) and the transfinite (Cantor, set theory), and one that avoids the paradoxes of the infinite. [6, p. 72]

Concerning the actual infinite, Arthur claims in 2019 that

[A]ctual infinite syncategorematically understood ... as a distributive whole ... constitutes a perfectly clear and consistent third alternative in the foundations of mathematics. [6, p. 106]

\footnotetext{
${ }^{8}$ This point is explained in note 6 .

${ }^{9}$ The misconception concerning infinitesimals being necessarily zero has already been analyzed in notes 4] and 6] Note that in 1989 and 1990 Knobloch presented such definitions unaccompanied by any vanishing claims; see notes 2 and 3 .
} 
Arthur's proposal of such alternative foundations is based on a passage from a supplement to Leibniz's letter to des Bosses. Look and Rutherford translate this letter to des Bosses (number 10 in their collection [47]) as well as the "supplementary study" which contains the passage about "actual infinite in the sense of a distributive whole." In footnote 8 on page 409, Look and Rutherford note that this passage was "crossed through by Leibniz." This crossed-out comment is what Arthur is basing his "perfectly clear alternative foundations for mathematics" on. The reviewer for Zentralblatt observes:

[T]wo concerns of this paper seems to me not correct: 1) the idea that through the concept of the actually infinite division of matter and through the highlighted meaning of syncategorematic infinite a consistent conception of the actual infinite may be obtained; 2) Cantor's conception and theory of transfinite is inconsistent. (Bussotti [20])

4.1. Evolution of Arthur's views. Arthur's views concerning mathematical actual infinity in Leibniz appear to have undergone a significant evolution. In 2009, he claimed the following:

In many quarters, to boot, [Leibniz's] mature view is seen as somewhat unfortunate, especially since the work of Abraham Robinson and others in recent years, which has succeeded in rehabilitating infinitesimals as actual, non-Archimedean entities. A dissenting view has been given by Ishiguro, who argues (in my opinion, persuasively) that Leibniz's syncategorematic interpretation of infinitesimals as fictions is a conceptually rich, consistent, finitist theory, well motivated within his philosophy, and no mere last-ditch attempt to safeguard his theory from foundational criticism. [2, p. 11] (emphasis on 'actual' added)

Accordingly, it is only in Robinson-influenced quarters that there is any talk of infinite actuality; in Ishiguro's "persuasive" view, infinitesimals are part of a "finitist theory." Similarly in 2013, Arthur writes:

I take the position here (following Ishiguro 1990) that the idea that Leibniz was committed to infinitesimals as actually infinitely small entities is a misreading: his mature interpretation of the calculus was fully in accord with the Archimedean Axiom. ... Infinitesimals ... really stand for variable finite quantities that can be taken as small as desired. [3, p. 554] (emphasis added)

Here again, actuality is reported to be a "misreading." 
Starting no later than 2014, we begin to find references to the syncategorematic actual infinite in mathematics:

There is an actual infinite, but it must be understood syncategorematically: to say that a series has infinitely many terms means not that it has $N$ terms where $N$ is greater than any finite number, but that for any finite $N$ it has more terms than that, 'more terms than one can specify'. [4, p. 88] (emphasis on 'syncategorematically' in the original; emphasis on 'actual' added)

Arthur adequately explains the point about 'more terms than $N$ ' but provides no evidence for his actual claim. Pace Arthur, Robinson specifically emphasized that Leibniz accepted only potential syncategorematic infinity of mathematical series:

[A]lthough Leibniz wishes to make it clear that he can dispense with infinitely small and infinitely large numbers and at any rate does not ascribe to them any absolute reality, he accepts the idea of potential ('syncategorematic') infinity and finds it in the totality of terms of a geometrical progression. (Robinson [52], 1966, p. 263)

A similar view is expressed in (Robinson [53, 1967, p. 35) 10 Robinson's position is compatible with those of other Leibniz scholars including Antognazza [1]; see [30, Section 2.3].

Arthur's claim concerning actual infinity in Leibniz involves a conflation of the two realms of (1) mathematics and (2) nature, since Leibnizian actual infinity (understood distributively) pertains only to the latter.

4.2. 'Testament to the necessity of infinite number'. In 39 pages, Arthur's 2019 text firmly establishes that Leibniz would have rejected Cantorian infinite cardinalities because they contradict the part-whole principle 11 This "transcription" [6, p. 72] of an afterlife Cantor-Leibniz

\footnotetext{
${ }^{10}$ For a formalisation of the Leibnizian calculus in Robinson's framework, see 24.

${ }^{11} \mathrm{~A}$ point already made by Ishiguro in 1990 ("Leibniz did not think that there should be what we call the cardinality of the set of all things" [28, p. 80]) as well as earlier authors; see e.g., Russell ([54, 1903, p. 210, end of item 140). Russell claims further that "if there were no infinite wholes, the word Universe would be wholly destitute of meaning" (ibid.). Russell accepted, as a matter of ontological certainty, Cantor's position both concerning the existence of infinite wholes and the nonexistence of infinitesimals. For an analysis of a dissenting opinion by contemporary neo-Kantians see [49.
} 
dialogue seeks to graft a passage from the letter to Masson upon the infinitesimal calculus. A fragment of the dialogue runs as follows:

Cantor: ... And what about your Infinitesimal Calculus? You must agree that this is a testament to the necessity of infinite number for mathematics!

Leibniz: On the contrary, in spite of my Infinitesimal Calculus, I admit no genuine (véritable) infinite number, even though I confess that the multiplicity (multitude) of things surpasses every finite number ...

(Cantor and Leibniz as transcribed by Arthur in [6], 2019, p. 74)

In his note 11 on page 74, Arthur sources the Leibnizian passage above in the 1716 letter to Masson. However, the Leibnizian passage is taken out of context. Arthur exploits the passage to suggest that Leibniz abstained from using infinite quantities in his calculus. The passage, taken out of context, can be read that way. In fact Leibniz does not mean to suggest such abstinence. While we don't disagree with Arthur that Leibniz may have rejected Cantorian infinite cardinalities, he did use infinite quantities that are mentis fictiones (that may be impossible in nature), as argued in [30]. Thus Arthur's "pastiche" [6, Note 1] tends to misrepresent Leibniz' philosophical stance with regard to infinities.

Leaving aside the question whether Georg Cantor - who referred to non-Archimedean number systems as the "infinite cholera bacillus" 12 of mathematics 13 - would be likely to press their case (i.e., the case

\footnotetext{
${ }^{12}$ In the original German: diesen infinitären Cholera-Bacillus [48, p. 505].

${ }^{13}$ Cantor names Thomae specifically. See Ehrlich ([22], 2006, p. 55) for an analysis of Thomae's non-Archimedean mathematics; see also Błaszczyk and Fila [16]. In the same letter, Cantor writes:

Professor Veronese (who, if I am not mistaken, emerged from the famous school of Professor Felix Klein, whom he also revered as a mighty mathematical hero), on the shoulders of those German predecessors in connection with the superficial and unclear ideas of his just mentioned teacher, finally built up his new theory of the actual infinitely small segments and claimed to have created by these a new foundation for geometry. ([48, p. 505]; translation ours)
}

Cantor's disdainful comments on Klein are all the more surprising since Klein was the one who came to Cantor's rescue when the latter was unable to publish his set-theoretic research in Berlin, and rapidly published a series of papers by Cantor in Mathematische Annalen. For further details on Klein's modernity see [12]. 
of the infinite numbers in the calculus) in a séance after his demise 14 one notes a conflation of the issue of Leibnizian opposition to infinite wholes (entailing, as argued by Arthur, a rejection of Cantorian infinite cardinalities); and the well-founded fictionality of his infinitesimal and infinite quantities.

The unique form of Arthur's medium, and the artistic licence it grants itself, do not yet justify playing loose with the philosophical positions of both Cantor and Leibniz.

\section{CONCLUSiOn}

We presented three case studies illustrating the fact that current received Leibniz scholarship routinely denies the Leibnizian infinitesimals the status of mathematical entities violating Euclid V Definition 4. We highlighted some difficulties that such interpretations encounter relative to the Leibnizian texts. Such difficulties do not arise for interpretations of Leibnizian infinitesimals that accord them the status of mathematical entities, that have recently appeared in the scholarly literature; see e.g., [8], [23, pp. 620, 641], 30], 31.

\section{ACKNOWLEDGMENT}

The influence of Hilton Kramer (1928-2012) is obvious.

\section{REFERENCES}

[1] Antognazza, M. The hypercategorematic infinite. The Leibniz Review 25 (2015), 5-30.

[2] Arthur, R. Actual infinitesimals in Leibniz's early thought, 11-28 in The Philosophy of the Young Leibniz, Studia Leibnitiana Sonderhefte 35, ed. Mark Kulstad, Mogens Laerke and David Snyder, Stuttgart: Franz Steiner, 2009.

[3] Arthur, R. Leibniz's syncategorematic infinitesimals. Archive for History of Exact Sciences 67 (2013), no. 5, 553-593. Zbl 1273.01021, MR3085673

[4] Arthur, R. Leibniz. Cambridge: Polity Press, 2014.

[5] Arthur, R. Leibniz's actual infinite in relation to his analysis of matter. In G.W. Leibniz, interrelations between mathematics and philosophy, Archimedes, 41, Springer, Dordrecht, 2015, pp. 137-156. MR3379808

[6] Arthur, R. Leibniz in Cantor's Paradise. In Leibniz and the Structure of Sciences. Modern Perspectives on the History of Logic, Mathematics, Epistemology, 71-109. Ed. V. De Risi, Boston Studies in Philosophy and History of Science, Cham: Springer, 2019. Zbl 1448.01010

\footnotetext{
${ }^{14}$ Cantor was, of course, interested in infinite cardinalities and sometimes referred to them as numbers, but these are clearly not the infinite numbers of Infinitesimal Calculus that he is presented as a champion of in this fragment of Arthur's séance. Leibniz already clearly understood the difference between multitude and magnitude.
} 
[7] Bair, J.; Błaszczyk, P.; Ely, R.; Henry, V.; Kanovei, V.; Katz, K.; Katz, M.; Kutateladze, S.; McGaffey, T.; Reeder, P.; Schaps, D.; Sherry, D.; Shnider, S. Interpreting the infinitesimal mathematics of Leibniz and Euler. Journal for General Philosophy of Science 48 (2017), no. 2, 195238. http://dx.doi.org/10.1007/s10838-016-9334-z, https://arxiv. org/abs/1605.00455 MR3663035

[8] Bair, J.; Błaszczyk, P.; Ely, R.; Katz, M.; Kuhlemann, K. Procedures of Leibnizian infinitesimal calculus: An account in three modern frameworks. British Journal for the History of Mathematics 36 (2021), no. 3, 170-209. https://doi.org/10.1080/26375451.2020.1851120, https:// arxiv.org/abs/2011.12628 MR4353153

[9] Bair, J.; Błaszczyk, P.; Fuentes Guillén, E.; Heinig, P.; Kanovei, V.; Katz, M. Continuity between Cauchy and Bolzano: Issues of antecedents and priority. British Journal for the History of Mathematics 35 (2020), no. 3, 207-224. https://doi.org/10.1080/26375451.2020.1770015, https:// arxiv.org/abs/2005.13259 MR4154872

[10] Bair, J.; Błaszczyk, P.; Heinig, P.; Kanovei, V.; Katz, M. 19th century real analysis, forward and backward. Antiquitates Mathematicae 13 (2019), 1949. http://doi.org/10.14708/am.v13i1.6440, https://arxiv.org/abs/ 1907.07451 MR4075256

[11] Bair, J.; Błaszczyk, P.; Heinig, P.; Kanovei, V.; Katz, M. Cauchy's work on integral geometry, centers of curvature, and other applications of infinitesimals. Real Analysis Exchange 45 (2020), no. 1, 127-150. https://doi. org/10.14321/realanalexch.45.1.0127, https://arxiv.org/abs/2003. 00438 MR4196072

[12] Bair, J.; Błaszczyk, P.; Heinig, P.; Katz, M.; Schäfermeyer, J.; Sherry, D. Klein vs Mehrtens: restoring the reputation of a great modern. Mat. Stud. 48 (2017), no. 2, 189-219. https://arxiv.org/abs/1803.02193, http:// doi.org/10.15330/ms.48.2.189-219 MR3819950

[13] Bascelli, T.; Błaszczyk, P.; Kanovei, V.; Katz, K.; Katz, M.; Schaps, D.; Sherry, D. Leibniz versus Ishiguro: Closing a Quarter Century of Syncategoremania. HOPOS: The Journal of the International Society for the History of Philosophy of Science 6 (2016), no. 1, 117-147.http://doi.org/10.1086/ 685645, https://arxiv.org/abs/1603.07209

[14] Bassler, O. Leibniz on the indefinite as infinite. The Review of Metaphysics 51 (1998), no. 4, 849-874.

[15] Blåsjö, V. Transcendental curves in the Leibnizian calculus. Studies in the History of Mathematical Enquiry. Elsevier/Academic Press, [London], 2017. Zbl 1381.01001, MR3645029

[16] Błaszczyk, P.; Fila, M. Cantor on infinitesimals. Historical and modern perspective. Bulletin of the Section of Logic 49/2 (2020), 149-179. http://dx. doi.org/10.18778/0138-0680.2020.09

[17] Błaszczyk, P.; Kanovei, V.; Katz, M.; Sherry, D. Controversies in the foundations of analysis: Comments on Schubring's Conflicts. Foundations of Science 22 (2017), no. 1, 125-140. http://doi.org/10.1007/s10699-015-9473-4, https://arxiv.org/abs/1601.00059 Zbl 1368.01021, MR3605125

[18] Breger, H. Das Kontinuum bei Leibniz. In L'infinito in Leibniz, Problemi e terminologia, Simposio Internazionale Roma, 6-8 novembre 1986, a cura di 
Antonio Lamarra, pp. 53-67. Roma: Edizioni dell' Ateneo, 1990. Reprinted as Breger [19].

[19] Breger, H. Das Kontinuum bei Leibniz. In W. Li (Ed.), Kontinuum, analysis, informales-Beiträge zur Mathemathik und Philosophie von Leibniz, pp. 115126. Berlin-Heidelberg: Springer, 2016. Zbl 1368.01005, MR3917131

[20] Bussotti, P. Review of Arthur 6] for Zentralblatt (2019). https://zbmath. org $/ ? q=a n \% 3 A 07217301$

[21] De Risi, V. (Ed.) Leibniz and the Structure of Sciences. Modern Perspectives on the History of Logic, Mathematics, Epistemology. Cham: Springer, 2019. Zbl 1432.01007, MR4352411

[22] Ehrlich, P. The rise of non-Archimedean mathematics and the roots of a misconception. I. The emergence of non-Archimedean systems of magnitudes. Archive for History of Exact Sciences 60 (2006), no. 1, 1-121. Zbl 1086.01024, MR2206281

[23] Esquisabel, O.; Raffo Quintana, F. Fiction, possibility and impossibility: Three kinds of mathematical fictions in Leibniz's work. Archive for History of Exact Sciences 75 (2021), no. 6, 613-647. https://doi.org/10.1007/ s00407-021-00277-0 Zbl 07433736, MR4324748

[24] Fletcher, P.; Hrbacek, K.; Kanovei, V.; Katz, M.; Lobry, C.; Sanders, S. Approaches to analysis with infinitesimals following Robinson, Nelson, and others. Real Analysis Exchange 42 (2017), no. 2, 193-252. https:// arxiv.org/abs/1703.00425, http://doi.org/10.14321/realanalexch. 42.2.0193 MR3721800

[25] Gerhardt, C. (ed.) Die philosophischen Schriften von Gottfried Wilhelm Leibniz. Berlin: Weidmann 1875-1890 (cited as [GP]).

[26] Gerhardt, C. (ed.) Leibnizens mathematische Schriften. Berlin: Asher and Halle: H.W. Schmidt, 1849-63 (cited as [GM]).

[27] Goldenbaum, U.; Jesseph, D. (Eds.) Infinitesimal Differences. Controversies between Leibniz and his Contemporaries. Berlin New York: Walter de Gruyter, 2008.

[28] Ishiguro, H. Leibniz's philosophy of logic and language. Second edition. Cambridge: Cambridge University Press, 1990.

[29] Jesseph, D. Philosophical theory and mathematical practice in the seventeenth century. Stud. Hist. Philos. Sci. 20 (1989), no. 2, 215-244. Zbl 0681.01006

[30] Katz, M.; Kuhlemann, K.; Sherry, D.; Ugaglia, M. Leibniz on bodies and infinities: rerum natura and mathematical fictions. Review of Symbolic Logic (2022). https://www.doi.org/10.1017/S1755020321000575, https://arxiv.org/abs/2112.08155

[31] Katz, M.; Kuhlemann, K.; Sherry, D.; Ugaglia, M.; van Atten, M. Two-track depictions of Leibniz's fictions. The Mathematical Intelligencer (2022). https://doi.org/10.1007/s00283-021-10140-3, https://arxiv. org/abs/2111.00922

[32] Katz, M., Sherry, D. Leibniz's infinitesimals: Their fictionality, their modern implementations, and their foes from Berkeley to Russell and beyond. Erkenntnis 78 (2013), no. 3, 571-625. http://dx.doi.org/10.1007/ s10670-012-9370-y, http://arxiv.org/abs/1205.0174 MR3053644 
[33] Knobloch, E. Übersicht über die unveröffentlichten mathematischen Arbeiten von Leibniz (1672-1676) mit einem Anhang über die ersten Ansätze zur algebraischen Indexbezeichnung während der Pariser Zeit. Leibniz in Paris (16721676) (Sympos. G. W. Leibniz Soc./CNRS, Chantilly, 1976), Vol. I, pp. 3-43, Studia Leibnitiana Suppl., XVII. Wiesbaden: Steiner, 1978. MR0594599

[34] Knobloch, E. Progrès et tâches futures de la recherche Leibnizienne en mathématiques. Les Études philosophiques, avril-juin 1989, no. 2, Leibniz (avril-juin 1989), pp. 161-170.

[35] Knobloch, E. L'infini dans les mathématiques de Leibniz. In L'infinito in Leibniz, Problemi e terminologia, Simposio Internazionale Roma, 6-8 novembre 1986, a cura di Antonio Lamarra, pp. 33-51. Roma: Edizioni dell' Ateneo, 1990.

[36] Knobloch, E. The infinite in Leibniz's mathematics - The historiographical method of comprehension in context. In K. Gavroglu, J. Christianidis, E. Nicolaidis (eds.), Trends in the historiography of science, pp. 265-278. Dordrecht: Kluwer, 1994.

[37] Knobloch, E. Galileo and Leibniz: different approaches to infinity. Archive for History of Exact Sciences 54 (1999), no. 2, 87-99. MR1705300

[38] Knobloch, E. Leibniz's rigorous foundation of infinitesimal geometry by means of Riemannian sums. Foundations of the formal sciences, 1 (Berlin, 1999). Synthese 133 (2002), no. 1-2, 59-73. Zbl 1032.01011, MR1950043

[39] Knobloch, E. Generality and infinitely small quantities in Leibniz's mathematics - The case of his arithmetical quadrature of conic sections and related curves. In Goldenbaum-Jesseph [27, 2008, pp. 171-183.

[40] Knobloch, E. Leibniz and the infinite. Doc. Math. 2012, Extra vol.: Optimization stories, 19-23. Zbl 1267.01019, MR2991464

[41] Knobloch, E. Leibniz and the infinite. Quaderns d'Història de l'Enginyeria 14 (2018), 11-31.

[42] Knobloch, E. On the relationship between point, indivisible, and infinitely small in western mathematics. Advanced Studies in Pure Mathematics $\mathbf{7 9}$ (2018), Mathematics of Takebe Katahiro and History of Mathematics in East Asia, pp. 39-58. Zbl 1436.01004, MR3931008

[43] Knobloch, E. Leibniz's Parisian studies on infinitesimal mathematics. In Navigating Across Mathematical Cultures And Times: Exploring The Diversity Of Discoveries And Proofs. Ioannis M. Vandoulakis and Dun Liu, Eds. (to appear; 2022?). See summary at https://doi.org/10.1142/9633

[44] Leibniz, G.W. Letter to Varignon, 20 june 1702. In Gerhardt [26], vol. IV, pp. 106-110.

[45] Leibniz, G.W. Letter to Samuel Masson (1716). In Gerhardt [25], vol. VI, pp. 624-629. Translated in Ariew-Garber's Leibniz [46], pp. 225-230.

[46] Leibniz, G.W. Philosophical essays. Translated and edited by Roger Ariew and Daniel Garber. Indianapolis: Hackett Publishing, 1989. https://books. google.co.il/books?id=1xEeAt6FU18C

[47] Leibniz, G.W. The Leibniz-Des Bosses Correspondence. Translated, edited, and with an Introduction by Brandon C. Look and Donald Rutherford. New Haven: Yale University Press, 2007.

[48] Meschkowski, H. Aus den Briefbüchern Georg Cantors. Archive for History of Exact Sciences 2 (1965), 503-519. Zbl 0139.00407, MR0195670 
[49] Mormann, T.; Katz, M. Infinitesimals as an issue of neo-Kantian philosophy of science. HOPOS: The Journal of the International Society for the History of Philosophy of Science 3 (2013), no. 2, 236-280. http://doi.org/10.1086/ 671348, https://arxiv.org/abs/1304.1027

[50] Rabouin, D. Leibniz's rigorous foundations of the method of indivisibles Or How to Reason with Impossible Notions. In Vincent Jullien (Ed.), Seventeenth-Century Indivisibles Revisited, Science Networks. Historical Studies, Vol. 49. Basel: Birkhäuser, 2015, pp. 347-364.

[51] Rabouin, D.; Arthur, R. Leibniz's syncategorematic infinitesimals II: their existence, their use and their role in the justification of the differential calculus. Archive for History of Exact Sciences 74 (2020), 401-443. Zbl 1448.01009, MR4134915

[52] Robinson, A. Non-standard analysis. Amsterdam: North-Holland Publishing, 1966. Zbl 0151.00803, MR0205854

[53] Robinson, A. The metaphysics of the calculus. In Problems in the philosophy of mathematics, Proceedings of the International Colloquium in the Philosophy of Science, London, 1965, Vol. 1, edited by Imre Lakatos, North-Holland Publishing, Amsterdam, 1967, pp. 28-46. Zbl 0155.33603, MR0209101

[54] Russell, B. The Principles of Mathematics. Vol. I. Cambridge University Press, Cambridge, 1903. JFM 34.0062.14

[55] Schubring, G. Conflicts between generalization, rigor, and intuition. Number concepts underlying the development of analysis in 17-19th Century France and Germany. Sources and Studies in the History of Mathematics and Physical Sciences. New York: Springer-Verlag, 2005. Zbl 1086.01001, MR2144499

[56] Ugaglia, M. Possibility vs Iterativity: Leibniz and Aristotle on the Infinite. In Thinking and Calculating. Essays on Logic, its History and its Applications in honor of Massimo Mugnai, Francesco Ademollo, Fabrizio Amerini, Vincenzo De Risi (Eds.), Berlin, Springer 2022 (forthcoming).

M. Katz, Department of Mathematics, Bar Ilan University, Ramat GAN 5290002 IsRAEL

Email address: katzmik@math.biu.ac.il

K. Kuhlemann, Institute of Mathematics and Physics Education, GottFried Wilhelm Leibniz University Hannover, D-30167 Hannover, GerMANY

Email address: kus.kuhlemann@t-online.de

D. Sherry, Department of Philosophy, Northern Arizona UniverSity, FlagstafF, AZ 86011, US

Email address: David.Sherry@nau.edu

M. Ugaglia, Il Gallo Silvestre, Località Collina 38, Montecassiano, ITALY

Email address: monica.ugaglia@gmail.com 